\title{
Article
}

\section{Hyo-Mental Angle and Distance: An Important Adjunct in Airway Assessment of Adult Mucopolysaccharidosis}

\author{
Chaitanya Gadepalli ${ }^{1, *(\mathbb{D})}$, Karolina M. Stepien ${ }^{2}(\mathbb{D})$ and Govind Tol ${ }^{3}$ \\ 1 Ear Nose and Throat Department, Salford Royal NHS Foundation Trust, Manchester M6 8HD, UK \\ 2 Adult Inherited Metabolic Department, Salford Royal NHS Foundation Trust, Manchester M6 8HD, UK; \\ karolina.stepien@srft.nhs.uk \\ 3 Anaesthetics Department, Salford Royal NHS Foundation Trust, Manchester M6 8HD, UK; \\ govind.tol@srft.nhs.uk \\ * Correspondence: cgadepalli@gmail.com
}

check for updates

Citation: Gadepalli, C.; Stepien, K.M.; Tol, G. Hyo-Mental Angle and Distance: An Important Adjunct in Airway Assessment of Adult Mucopolysaccharidosis. J. Clin. Med. 2021, 10, 4924. https://doi.org/ $10.3390 / \mathrm{jcm} 10214924$

Academic Editor: César Picado

Received: 2 October 2021

Accepted: 21 October 2021

Published: 25 October 2021

Publisher's Note: MDPI stays neutral with regard to jurisdictional claims in published maps and institutional affiliations.

Copyright: (c) 2021 by the authors. Licensee MDPI, Basel, Switzerland. This article is an open access article distributed under the terms and conditions of the Creative Commons Attribution (CC BY) license (https:/ / creativecommons.org/licenses/by/ $4.0 /)$.

\begin{abstract}
Background: Mucopolysaccharidosis (MPS) is a rare congenital lysosomal storage disorder with complex airways. High anterior larynx is assessed by thyromental distance (TMD) nasendoscopy. A simpler method to assess this hyoid bone is described. The distance between the central-hyoid and symphysis of the mandible (hyo-mental distance; HMD) and inclination of this line to the horizontal axis (hyo-mental angle; HMA) in neutrally positioned patients is investigated. Methods: HMA, HMD in MPS, and non-MPS were compared, and their correlation with height and weight were assessed. Results: 50 adult MPS patients $(\mathrm{M}=32, \mathrm{~F}=18$, age range $=19-66$ years; mean BMI $\left.=26.8 \mathrm{~kg} / \mathrm{m}^{2}\right)$ of MPS I, II, III, IV, and VI were compared with 50 non-MPS $(\mathrm{M}=25, \mathrm{~F}=25$; age range $=22-84$ years; mean BMI $\left.=26.5 \mathrm{~kg} / \mathrm{m}^{2}\right)$. Mean HMA in MPS was $25.72^{\circ}(-10$ to +50$)$ versus $2.42^{\circ}(-35$ to +28$)$ in non-MPS. Mean HMD was 46.5 (25.7-66) millimeters in MPS versus 41.8 (27-60.3) in non-MPS. HMA versus height and weight showed a moderate correlation $(\mathrm{r}=-0.4$, $p<0.05)$ in MPS and no significant correlation $(r<0.4, p>0.05)$ in non-MPS. HMD versus height and weight showed no correlation $(r<0.4, p>0.05)$ in both groups. Conclusions: HMA seems more acute in MPS despite nearly the same HMD as non-MPS, signifying a high larynx, which may be missed by TMD.
\end{abstract}

Keywords: mucopolysaccharidosis; airway management; radiology; hyoid bone; chin; intubation; intratracheal

\section{Introduction}

Mucopolysaccharidosis are a group of inherited congenital multisystem diseases due to a deficiency in enzymes required for the breakdown of complex mucopolysaccharides. Mucopolysaccharidoses (MPSs) are rare, inherited, lysosomal storage diseases with a combined incidence of 1 in 22,000 [1]. The disease is characterized by the accumulation of glycosaminoglycans (GAGs) in almost all parts of the body. There are seven types of MPS depending on the type of enzyme deficiency (Table 1). The manifestations of this disease are multisystemic, resulting in shortened longevity [2]. Along with other systems, airways are commonly involved. Knowledge about the airway abnormalities is important as these patients can pose airway problems. With advances in treatment modalities, such as hematopoietic stem cell transplantation (HSCT) [3] and enzyme replacement therapy (ERT) [4], the longevity of these patients has increased posing newer problems. Most of these patients will need general anesthetic for surgery at some point in their lifetime due to multi-system involvement. In our experience, we noted that most adult MPS patients have a large and bulky tongue, large lower jaw, and short neck [5]. A high or anterior larynx poses difficulty in access to the airway. A difficult laryngoscopy is defined as an inability to visualize any part of the vocal cords on conventional laryngoscopy [6]. Various bedside measures have been described to assess a high or anterior larynx. The method commonly 
used to assess a high or anterior larynx are measurement of the thyromental distance TMD [7], nasendoscopy, or cross-sectional imaging. TMD is the distance between the chin, also called the mentum, and prominence of the thyroid cartilage with the neck extended. TMD [7] is about $6.5 \mathrm{~cm}$ measured with an intubation gauze or three finger breadths. Direct visualization of the oropharynx and larynx via a fiber optic scope, also called nasendoscopy, can also estimate a high larynx. Figure 1 shows a nasendoscopy picture of a patient with a normal larynx. Figure 2 shows a nasendoscopy picture in an MPS I patient and Figure 3 shows a nasendoscopy picture in an MPS II patient. Cross-sectional imaging either with a computer tomography scan (CT) or magnetic resonance imaging (MRI) provides a detailed evaluation of the head and neck in a neutral position. Many times, these scans have been performed in MPS patients for their co-morbidities. We propose a simpler and possibly more accurate method of assessing a high or anterior larynx using existing cross-section imaging of the neck. This information is very helpful in planning any airway intervention or general anesthetic. We use the body of the hyoid bone as a stable landmark: the distance from the center of the body of hyoid to the symphysis mentum of the mandible is the hyomental distance (HMD). The inclination or declination of HMD to the horizontal axis is the hyomental angle (HMA). The HMD quantifies the anterior larynx and HMA identifies the high larynx. Figure 4 shows a sagittal section diagram showing the landmarks and Figure 5 shows HMA and HMD on a CT scan in a non-MPS and MPS patient. Figure 6 is a three-dimensional reconstruction of the upper body skeleton, showing the level of the hyoid bone in a non-MPS and MPS patient in relation to the mandible. The primary aim of this study was to identify a different and possibly a more accurate method to assess a high or anterior larynx and discuss its usefulness in airway management in adult MPS. The secondary aim was to assess the relationship of the body habitus to a high and anterior larynx.

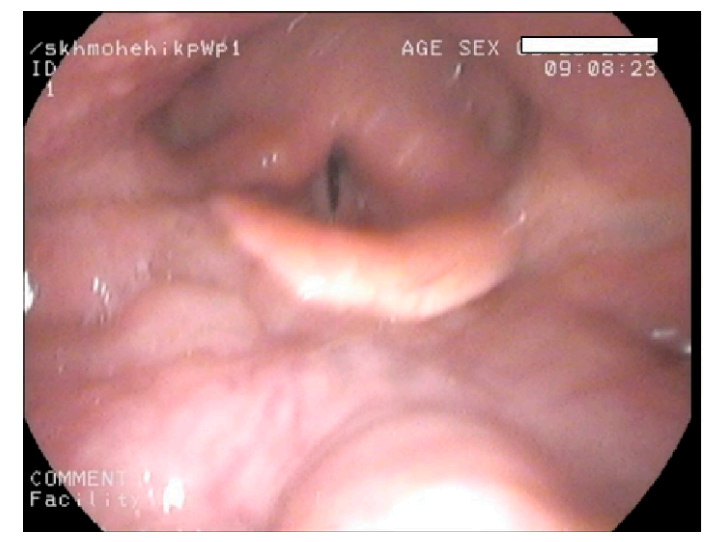

Figure 1. Nasendoscopy pictures showing a normal larynx: the vallecula, epiglottis, glottic inlet, and posterior larynx can be clearly seen.

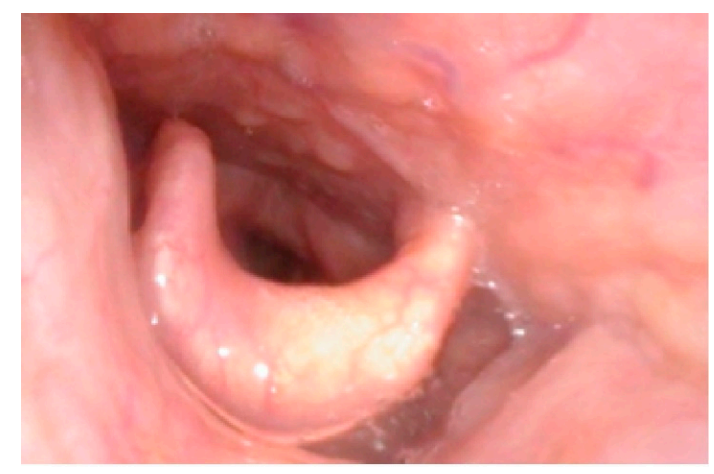

Figure 2. Nasendoscopy picture in MPS I showing a high larynx, large epiglottis touching the soft palate, vallecula cannot be seen, and only the posterior glottis is visible. 
Table 1. Various types of MPS; reproduced with permission from Braunlin et al. [8], who compiled data from Neufeld et al. [9] and Valayannopoulos et al. [10]. AR: autosomal recessive; CS: chondroitin sulfate; DS: dermatan sulfate; GAG: glycosaminoglycan; H: Hurler syndrome; HS: heparan sulfate; H-S: Hurler-Scheie syndrome; KS: keratan sulfate; S: Scheie syndrome; XR: X-linked recessive. * only 1 patient reported in the literature (Natowicz et al. 1996); ${ }^{* *}$ death can occur in utero with hydrops fetalis.

\begin{tabular}{|c|c|c|c|c|c|}
\hline $\begin{array}{l}\text { MPS Type } \\
\text { (Eponym) }\end{array}$ & $\begin{array}{c}\text { Incidence per } 10^{5} \\
\text { Live Births; } \\
\text { Inheritance Pattern }\end{array}$ & $\begin{array}{l}\text { Typical Age at } \\
\text { Diagnosis }\end{array}$ & $\begin{array}{l}\text { Typical Life } \\
\text { Expectancy If } \\
\text { Untreated }\end{array}$ & Enzyme Deficiency & GAG \\
\hline $\begin{array}{c}\text { MPS I Hurler (H) } \\
\text { MPS I } \\
\text { Hurler-Scheie (H-S) } \\
\text { MPS I Scheie (S) }\end{array}$ & $0.11-1.67 ; \mathrm{AR}$ & $\begin{array}{l}\mathrm{H}:<1 \text { year H-S: } 3-8 \\
\text { years S: } 10-20 \text { years }\end{array}$ & $\begin{array}{l}\text { H: death in } \\
\text { childhood H-S: } \\
\text { death in teens or } \\
\text { early adulthood S: } \\
\text { normal to slightly } \\
\text { reduced lifespan }\end{array}$ & $\alpha$-L-iduronidase & DS, HS \\
\hline MPS II (Hunter) & $0.1-1.07 ; \mathrm{XR}$ & $\begin{array}{l}1-2 \text { years when } \\
\text { rapidly progressing }\end{array}$ & $\begin{array}{l}\text { rapidly progressing: } \\
\text { death < } 15 \text { years } \\
\text { slowly progressing: } \\
\text { death in adulthood }\end{array}$ & iduronate-2-sulfatase & DS, HS \\
\hline $\begin{array}{l}\text { MPS III (Sanfilippo) } \\
\text { A-B-C-D }\end{array}$ & $0.39-1.89 ; \mathrm{AR}$ & $4-6$ years & $\begin{array}{l}\text { death in puberty or } \\
\text { early adulthood }\end{array}$ & $\begin{array}{l}\text { heparan sulfamidase } \\
\text { (A) N-acetyl- } \alpha \text {-D- } \\
\text { glucosaminidase (B) } \\
\text { acetyl-CoA- } \alpha \text { - } \\
\text { glucosaminidase } \\
\text { N-acetyltransferase (C) } \\
\text { N-acetylglucosamine-6- } \\
\text { sulfatase } \\
\text { (D) }\end{array}$ & HS \\
\hline $\begin{array}{l}\text { MPS IV (Morquio) } \\
\text { A-B }\end{array}$ & 0.15-0.47; AR & $1-3$ years & $\begin{array}{l}\text { death in childhood- } \\
\text { middle age }\end{array}$ & $\begin{array}{c}\mathrm{N} \text {-acetylgalactosamine- } \\
\text { 6-sulfatase (A) } \\
\beta \text {-galactosidase (B) }\end{array}$ & $\underset{\text { (B) }}{\mathrm{CS}, \mathrm{KS}(\mathrm{A}) \mathrm{KS}}$ \\
\hline $\begin{array}{c}\text { MPS VI } \\
\text { (Maroteaux-Lamy) }\end{array}$ & 0-0.38; AR & $\begin{array}{c}\text { rapidly progressing: } \\
\text { 1-9 years slowly } \\
\text { progressing: }>5 \\
\text { years }\end{array}$ & $\begin{array}{l}\text { rapidly progressing: } \\
\text { death in } 2 \text { nd-3rd } \\
\text { decade slowly } \\
\text { progressing: death } \\
\text { in 4-5th decade }\end{array}$ & $\begin{array}{c}\mathrm{N} \text {-acetylgalactosamine- } \\
\text { 4-sulfatase }\end{array}$ & DS \\
\hline MPS VII (Sly) & $0-0.29 ; \mathrm{AR}$ & $\begin{array}{l}\text { neonatal to } \\
\text { adulthood }\end{array}$ & $\begin{array}{l}\text { death in infancy-4th } \\
\text { decade ** }\end{array}$ & $\beta$-D-glucuronidase & CS, DS, HS \\
\hline MPS IX (Natowicz) & unknown & adolescence & unknown & hyaluronidase & CS \\
\hline
\end{tabular}

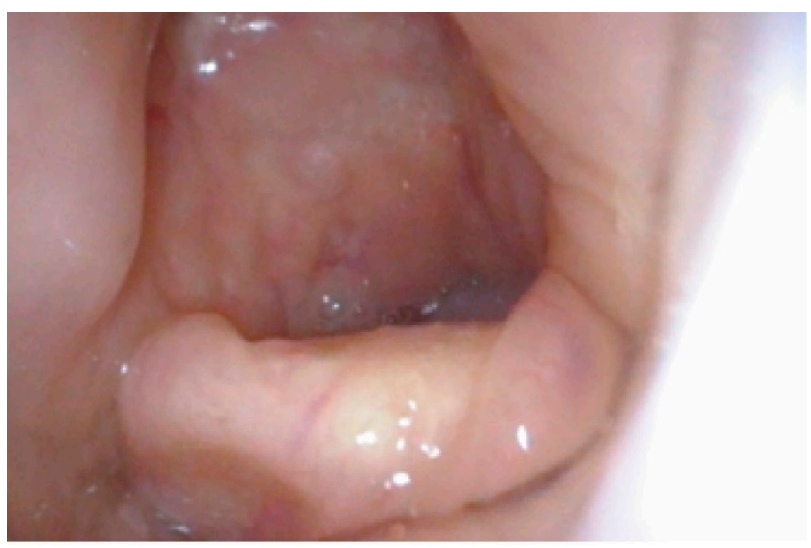

Figure 3. Nasendoscopy picture of MPS II showing a high and anterior larynx, epiglottis is touching the soft palate, vallecula is not seen, and only posterior pharyngeal wall is seen. 


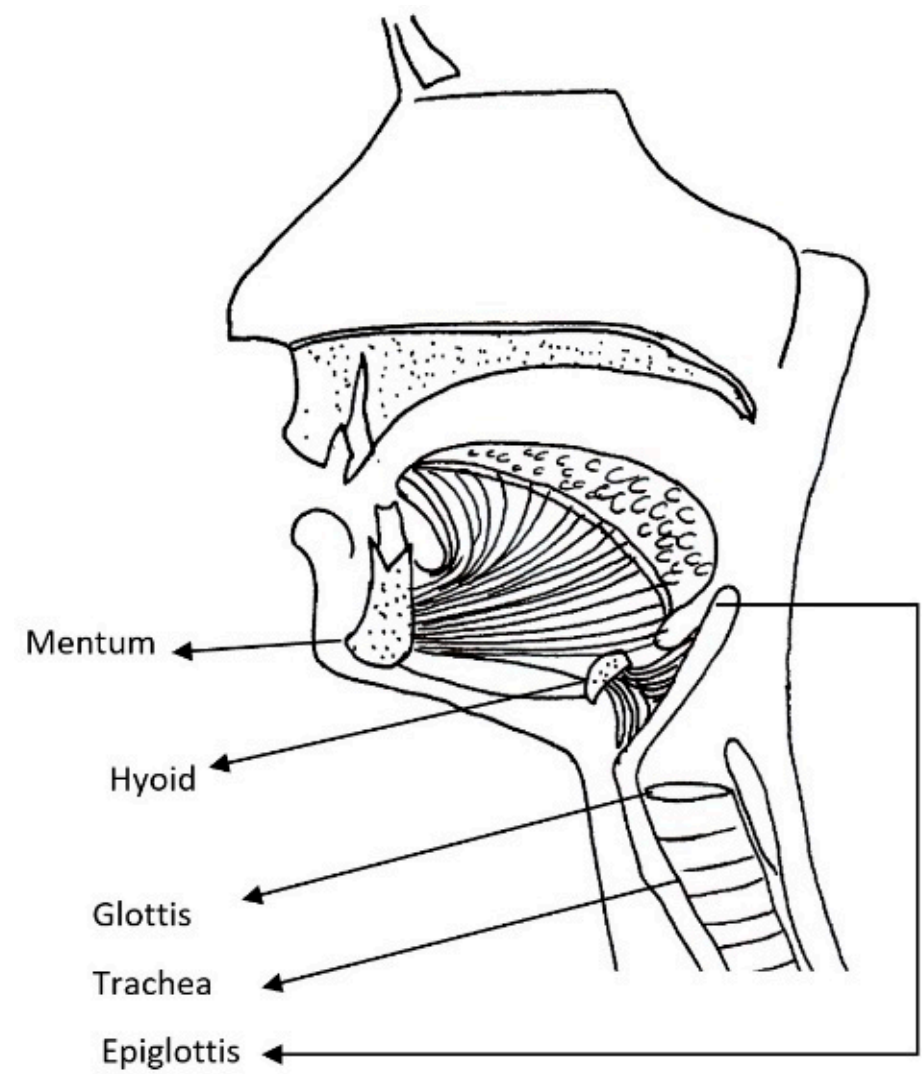

Figure 4. Line diagram sagittal section of the head and neck showing the upper airway and landmarks.

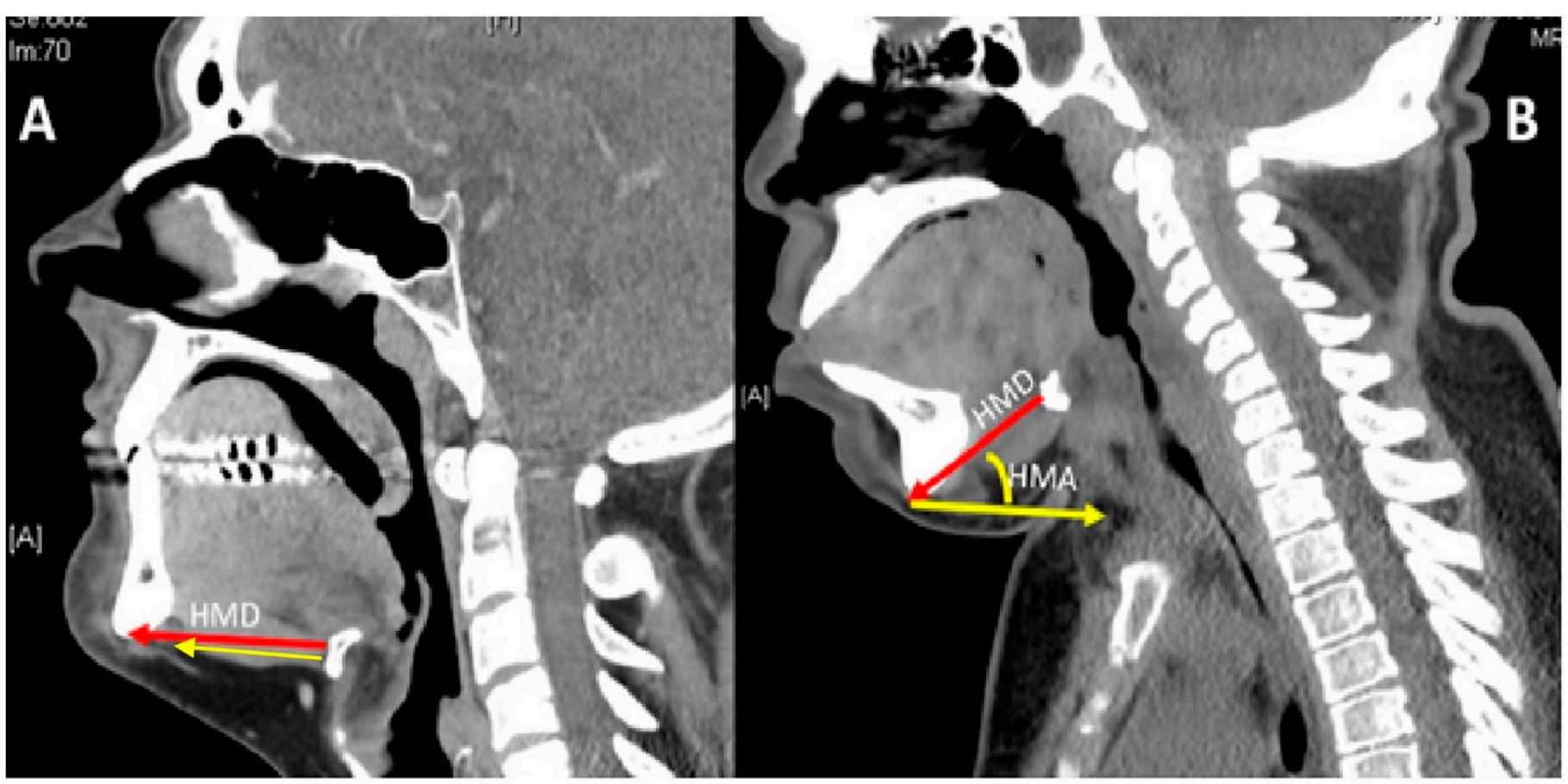

Figure 5. Shows the hyomental distance (HMD) and hyomental angle (HMA) in adult non-MPS marked (A) on the left and adult MPS patient marked (B) on the right, taken from a computer tomography (CT) scan of the neck in the neutral position. Red arrow represents the HMD and yellow arrow represents the horizontal. 


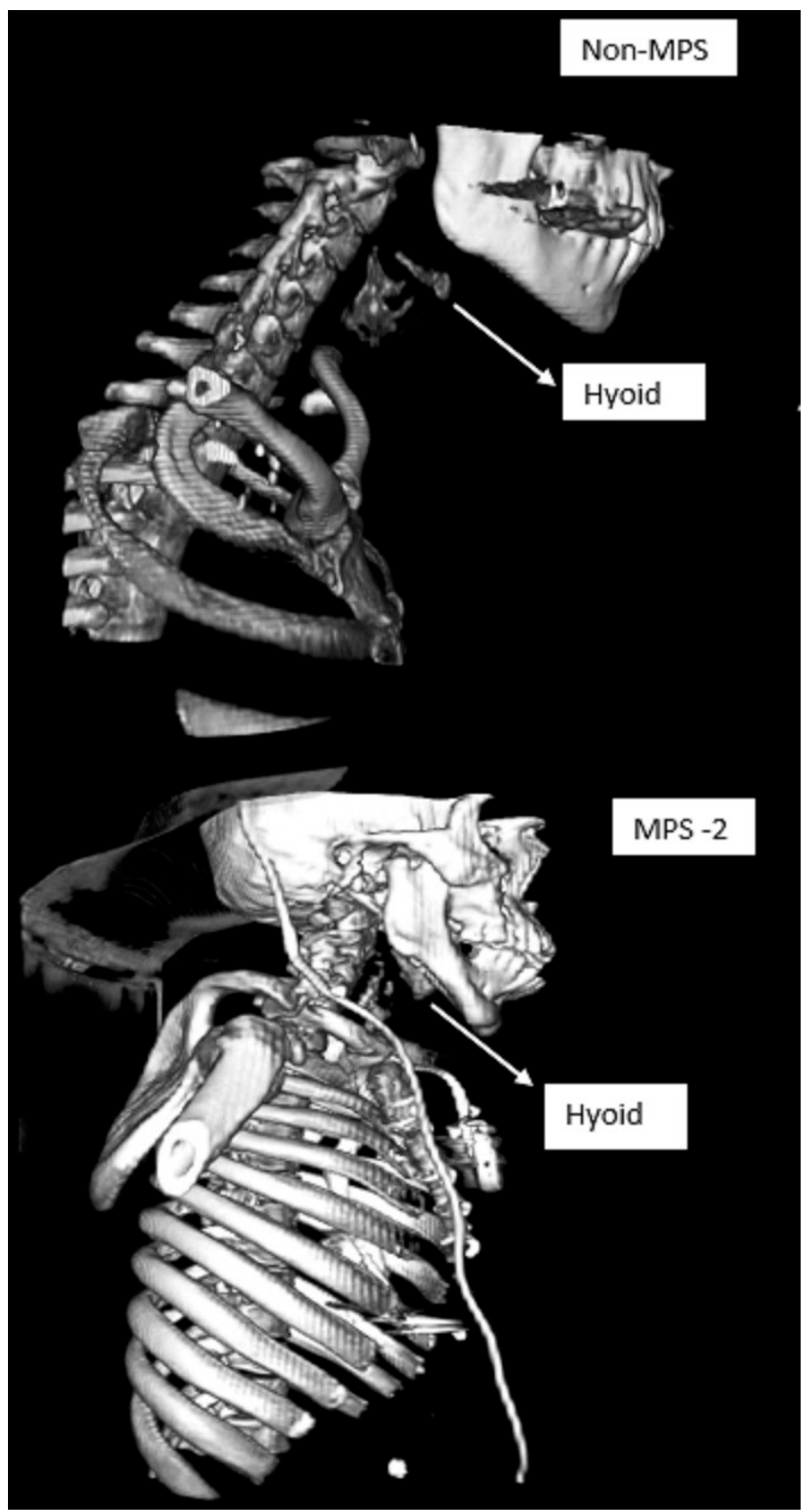

Figure 6. Three-dimensional reconstruction of the upper body skeleton, showing the level of hyoid bone in a non-MPS (top panel) and MPS-2 patient (lower panel) in relation to the mandible. A ventriculoperitoneal shunt and pacemaker are seen in the MPS patient. MPS- Mucopolysaccharidosis.

\section{Materials and Methods}

Retrospective analysis of case notes and radiological investigations was performed as part of routine care of 50 adult MPS patients and comparison with 50 healthy adults of similar age, gender, and body mass index (BMI). Ethical approval was obtained from the local research and innovation department, Salford Royal NHS Foundation Trust, Northern Care Alliance, United Kingdom, reference: S20HIP40. HMD and HMA were calculated for each 
group calculated in the picture archiving communications system (PACS) using the ruler tool. A smaller HMD was considered to be an anterior larynx and acute inclination of the HMA to the horizontal axis was considered to represent a high larynx. Both HMD and HMA reflect the difficulty in accessing an airway. The impact of body habitus on a high or anterior larynx was investigated by calculating the Pearsons correlation between HMD, HMD, and weight and height.

\section{Results}

Radiological cross-sectional images of 50 MPS and 50 non-MPS patients were included in the study. The MPS group included patients with types I, II, III, IV, and VI. Table 2 depicts the demographics in both groups. It may be noted that even though age does not match between both groups, BMI is comparable. The non-MPS group of patients included a range of patients of various ENT (ear, nose, and throat) pathologies who had imaging studies. All the patients in the non-MPS group had no pathology in the oral cavity, neck, oropharynx, supraglottis, and hypopharynx. The non-MPS group had a normal supra-glottic airway. This enabled us to investigate the abnormal hyomental region in MPS patients. Table 3 depicts the pathology subtypes in both groups. The HMA and HMD were calculated and compared between the two groups.

Table 2. Demographics of the study in both the MPS and non-MPS groups.

\begin{tabular}{ccc}
\hline & MPS & Non-MPS \\
\hline Number of patients & 50 & 50 \\
Males & 32 & 25 \\
Females & 18 & 25 \\
Age range in years & $19-66$ & $22-84$ \\
Mean age in years & 31.7 & 59.9 \\
Mean Body Mass index & 26.8 & 26.5 \\
\hline
\end{tabular}

MPS-Mucopolysaccharidosis.

Table 3. Clinical diagnosis of different patients in the MPS and non-MPS groups. MPSMucopolysaccharidosis.

\begin{tabular}{|c|c|c|c|}
\hline Pathology & Number & Males & Females \\
\hline \multicolumn{4}{|l|}{ MPS group } \\
\hline MPSI & 16 & 8 & 8 \\
\hline MPSII & 13 & 13 & 0 \\
\hline MPSIII & 1 & 1 & 0 \\
\hline MPSIV & 14 & 6 & 8 \\
\hline MPSVI & 6 & 4 & 2 \\
\hline Total & 50 & 32 & 18 \\
\hline \multicolumn{4}{|c|}{ Non-MPS group } \\
\hline Subglottic stenosis & 10 & 1 & 9 \\
\hline Tracheal stenosis & 8 & 5 & 3 \\
\hline Vasculitis & 7 & 4 & 3 \\
\hline Malignancy not involving supraglottis, oropharynx & 16 & 12 & 4 \\
\hline Bilateral vocal fold immobility & 5 & 0 & 5 \\
\hline Vocal cord leukoplakia & 4 & 3 & 1 \\
\hline Total & 50 & 25 & 25 \\
\hline
\end{tabular}

MPS-Mucopolysaccharidosis.

Table 4 depicts HMA and HMD in both MPS and non-MPS groups. It may be noted that the HMD is slightly less in the MPS depicting slightly anterior larynx in the MPS group. The HMA is more acute in the MPS group compared to the non-MPS group, depicting that larynx is higher in the MPS groups. The MPS group have a shorter stature and lower body mass, this is a recognized feature of MPS due to multisystemic involvement of the disease. 
Table 4. HMD and HMA in the MPS and non-MPS groups.

\begin{tabular}{|c|c|c|c|c|c|c|}
\hline \multicolumn{7}{|c|}{ MPS } \\
\hline & $\begin{array}{l}\text { Age in } \\
\text { Years }\end{array}$ & $\begin{array}{l}\text { HMD in } \\
\text { Millime- } \\
\text { ters }\end{array}$ & $\begin{array}{l}\text { HMA in } \\
\text { Degrees }\end{array}$ & $\begin{array}{c}\text { Height in } \\
\text { Centime- } \\
\text { ters }\end{array}$ & $\begin{array}{l}\text { Weight in } \\
\text { Kilograms }\end{array}$ & $\begin{array}{l}\text { Body } \\
\text { Mass } \\
\text { Index }\end{array}$ \\
\hline \multicolumn{7}{|l|}{$N=50$} \\
\hline Mean & 31.74 & 46.5 & 27.6 & 135.8 & 50.47 & 26.8 \\
\hline Median & 29.50 & 48.5 & 25.0 & 136.8 & 48 & 25.7 \\
\hline Range & $19-66$ & $25.7-66.0$ & -10.0 to 50 & 91.0-182 & $17.4-125.2$ & $16.5-43.6$ \\
\hline \multicolumn{7}{|c|}{ Non-MPS } \\
\hline & $\begin{array}{l}\text { Age in } \\
\text { Years }\end{array}$ & $\begin{array}{l}\text { HMD in } \\
\text { Millime- } \\
\text { ters }\end{array}$ & $\begin{array}{l}\text { HMA in } \\
\text { Degrees }\end{array}$ & $\begin{array}{c}\text { Height in } \\
\text { Centime- } \\
\text { ters }\end{array}$ & $\begin{array}{l}\text { Weight in } \\
\text { Kilograms }\end{array}$ & $\begin{array}{l}\text { Body } \\
\text { Mass } \\
\text { Index }\end{array}$ \\
\hline \multicolumn{7}{|l|}{$N=50$} \\
\hline Mean & 59.9 & 41.9 & 2.420 & 166.1 & 72.6 & 26.5 \\
\hline Median & 63 & 40.9 & 0.0 & 166.0 & 71.9 & 26.9 \\
\hline Range & 22-99 & $27.0-60.3$ & -35.0 to 28 & $150.0-188$ & $39.3-130$ & $14.2-47.3$ \\
\hline
\end{tabular}

HMD—Hyomental distance, HMA—Hyomental angle. MPS-Mucopolysaccharidosis.

It can be assumed that a bulky upper airway may be attributable to BMI, thereby affecting HMA or HMD. To test this hypothesis, the Pearson correlation between the BMI versus HMA and HMD was calculated and Table 5 depicts the results. HMD shows no correlation with height, weight, and BMI in the non-MPS group but reveals a statistically significant correlation with height and weight in MPS $(p=0.05 ; p=0.009)$. It must be noted that the rho value in the MPS group is only 0.3 at best. The Pearson correlation between HMA versus height and weight showed a moderate negative correlation in the MPS group and no correlation in the non-MPS group. Thus, HMA shows a better correlation with height and weight in the MPS group, compared to HMD. The significant results are highlighted in the table.

Table 5. Pearson correlation between HMA, HMD, height, weight, and BMI in both the MPS and non-MPS groups.

\begin{tabular}{|c|c|c|c|c|c|c|}
\hline \multicolumn{7}{|c|}{ Correlations MPS } \\
\hline & & HMD & HMA & HT & WT & BMI \\
\hline \multirow{2}{*}{ HMD } & rho & 1 & -0.2 & $0.28 *$ & $0.3^{*}$ & 0.2 \\
\hline & $p$-value & & 0.15 & $0.05 *$ & $0.009 *$ & 0.13 \\
\hline \multirow{2}{*}{ HMA } & rho & -0.2 & 1 & $-0.45 *$ & $-0.41 *$ & -0.1 \\
\hline & $p$-value & 0.146 & & 0.0001 * & $0.003 *$ & 0.73 \\
\hline \multicolumn{7}{|c|}{ Correlations Non-MPS } \\
\hline & & HMD & HMA & HT & WT & BMI \\
\hline \multirow{2}{*}{ HMD } & rho & 1 & 0.15 & 0.1 & 0.35 & 0.27 \\
\hline & $p$-value & & 0.3 & 0.49 & 0.014 & 0.06 \\
\hline \multirow{2}{*}{ HMA } & rho & 0.15 & 1 & -0.03 & -0.03 & 0.02 \\
\hline & $p$-value & 0.296 & & 0.85 & 0.862 & 0.91 \\
\hline
\end{tabular}

* Represents significant results. HMA—Hyomental angle, HMD—Hyomental distance, HT—height, WT—weight, BMI—Body Mass Index, rho-Pearsons correlation coefficient value.

\section{Discussion}

\subsection{Difficult Airway}

Airway complications are a common feature of MPS I, II, IV, and VI and considerably contribute to morbidity and premature mortality [11,12]. Airway assessment is ideally performed holistically, taking into account all the factors in the upper and lower airways 
with various methods, including medical history, clinical examination, radiological evaluation, and endoscopy [13]. A high and anterior larynx is one of the important aspects in the upper airway, which can lead to difficult intubation due to poor access, also called difficult laryngoscopy. Failure to recognize airway problems pre-operatively or during the planning of airway intervention can lead to unfavorable outcomes. MPS is a rare disease, and awareness amongst health professionals regarding adult MPS patients is poor. Once a patient is paralyzed and anaesthetized, the tongue falls backwards, and the oropharynx collapses inwards. In this situation, a high or an anterior larynx makes access to the larynx difficult if not impossible. In a patient who is paralyzed and anaesthetized, this can lead to situation of "cannot intubate- cannot ventilate". The Difficult Airway Society (DAS; UK) has produced guidelines on this difficult situation [14]. This difficult situation can be prevented by recognition of the problem of difficult access by existing cross-section images. Metanalysis of 35 studies representing 50,760 patients revealed the incidence of difficult intubation is about $5.8 \%$ in normal patients, $3.1 \%$ in obstetric patients, and 14.8 in obese patients [15]. This may be higher in MPS due to deposition of GAGs in the soft tissues and musculoskeletal system, leading to bulky upper airways and bony abnormalities. A combination of abnormalities in the soft tissue, cervical spine, and skull leads to a high larynx and anterior larynx, resulting in difficulty accessing the airway. In our study, an attempt was made to match the MPS and non-MPS groups. It is not possible to obtain an exact match as age-related changes are faster in the MPS group with a shortened life span. Most of the MPS patients have short stature; however, it can be noted that both MPS and non-MPS groups have nearly similar BMI. We must also understand that MPS patients have a short stature and have truncal obesity [16], and non-MPS patients in our group are taller. Hence, BMI may be a misleading airway health measure in MPS patients. The PACS has in-built tools to measure the distances and angles in the cross-sectional images. As this measurement tool is computerized, we can assume that inter or intra-rater variability is reduced. Bias may be observed if the landmarks are not correctly identified by the clinician. In situations where the clinician does not have access to PACS, an angle measure and a ruler can be used to obtain HMD or HMA on existing cross-sectional imaging. In our study, we note that HMD was slightly less in the MPS group, indicating that the larynx is mildly anterior. The overall difference, however, in HMD in the MPS and non-MPS groups is minimal. On the other hand, HMA was more acute in the MPS group, indicating that the larynx is higher in the MPS group. It is interesting to note that HMA can vary in the MPS group despite nearly the same HMD as non-MPS.

Moreover, it was observed that some MPS patients did not have acute HMA and nearly the same HMD as non-MPS. The reasons for this could be multifactorial. Firstly, 16 results from MPS type I had milder upper airway abnormalities; secondly, the severity of MPS is dependent on mutations, the length, or their therapies, such as enzyme replacement therapy (ERT) or hematopoietic stem cell transplantation (HSCT). ERT in MPS I HurlerScheie (HS) and Scheie, II, IVA, and VI and HSCT in MPS I Hurler (H) have demonstrated organ-specific and systemic metabolic correction [17-20]; hence, the severity of the disease is variable. Advances in treatment strategies have improved life expectancy, and the average age of our cohort was 31.7 years. So, our study may be representative of varied MPS phenotypes and younger adult MPS patients.

\subsection{Clinical Measures of Difficult Airway}

TMD is a commonly used tool in airway assessment. The sensitivity of TMD is about $25 \%$ (95\% confidence interval: $23-28$ ) and specificity is $90.2 \%$ (95\% confidence interval: 90 91) [21]. In MPS patients, the lower jaw may be disproportionately large, resulting in a normal thyromental distance despite a high and anterior larynx. TMD may also be of limited use in patients with facial and skeletal dysmorphism, and bulky soft tissues of the neck and sub mental region as commonly noted in adult MPS. The sternomental distance (SMD) [22] is calculated by measuring the distance between the mentum and the manubrium sternum with the mouth closed. It may indicate the degree of neck extension, which is important in access 
to the airway. The authors [22] conclude that a sternomental distance of $13.5 \mathrm{~cm}$ or less was $66.7 \%$ sensitive and $71.1 \%$ specific, and the positive and negative predictive values were $7.6 \%$ and $98.4 \%$, for difficult laryngoscopy [22]. In their study, there was no association between sternomental distance and age, weight, height, or BMI. Sternomental distance may indirectly reflect a high larynx, and further research can be done to invesitgate this association. The TMD and SMD may be normal in MPS patients due to a large lower jaw, giving a false sense of security of a normal airway. The distance between the hyoid and thyroid prominence may not be as variable, so HMD and TMD may represent the same measure. HMD may be more accurate as it does not take into account the sub cutaneous soft tissue of the neck. In our study, we observed that the HMD is nearly the same in the MPS and non-MPS groups but the HMA was more acute. This may indicate that HMA is a more accurate measure of a high or anterior larynx than HMD or TMD. The results of this study showed that there is no correlation between the HMA and HMD in both the MPS and non-MPS groups, suggesting that HMA may be a completely independent entity, not related to the distance between the mentum to the laryngeal framework. The HMA correlates negatively with height and weight but has no correlation with BMI. This is because correlation is a linear measure and BMI is weight divided by height squared. Hence, observing the weight and height independently may be more useful than BMI in airway assessments. This may be more relevant to the MPS population as they are known to have short stature and central obesity $[23,24]$. The other commonly used bedside airway assessments methods are neck movements, neck circumference, Wilson's score [25], mallampati [26], and modified mallampati grade [27]. Mallampati and modified mallampati grade assess the size of the tongue in relation to the opened oral cavity. Dalewski [28] et al., in a study of 129 adults, suggested the combination of Mallampati grade, CT scan upper airway volume, and Berlin score to calculate snoring and breathlessness. The authors noted a positive correlation between high modified mallampati grade, BMI, and reduced oxygen saturations and upper airway volume. The pre-operative assessment aims to assess the difficult airway and plan a difficult situation. Based on laryngoscopy views, Cormack [29] graded the airway into three grades: grade 1 being full view of the glottis, grade 2-partial view of the glottis, grade 3-only epiglottis is visible, and grade 4-neither epiglottis nor glottis are visible. Modifications $[25,30]$ of grade 2 resulted in $2 a$ being part of the glottis visible and $2 b$ being arytenoids or posterior cords only just visible. Cook [31] suggested the grading system as " $E$ " as easy view—grade 1 and $2 a$ " $R$ " restricted view—grade $2 b$ and 3a and " $D$ " difficult view - grade $3 \mathrm{~b}$ and 4 , where the grade being epiglottis can be elevated with a gum elastic bougie and $3 \mathrm{~b}$ being epiglottis cannot be elevated by a gum elastic bougie. Knowledge of a grade $\mathrm{R}$ or $\mathrm{D}$ prior to intubation in the pre-assessment clinics is very useful; HMD and HMA will provide this information. Radiology plays an important role in airway assessment for an anesthetist [32]. Although lateral radiographs, chest X-rays, and ultrasonography [33,34] are useful, in our experience, we found that the use of MRI scans is helpful in upper airways and CT scans in lower airways. The images from CT and MRI scans can be used to perform three-dimensional reconstruction of the airways in MPS [35] and perform virtual endoscopy. We also found nasendoscopy to be very useful in adult MPS [36]. Imaging of the airway is not routinely performed for unsuspected airway problems. Any additional investigations should be carefully considered, keeping patient comfort in mind. Although HMD has been reported [37] as a predictor of difficult airway in patients with cervical spondylosis, HMA, to the best of our knowledge, has not been reported so far. We feel that this easily available tool is an adjunct to airway assessment and can be adopted in adult MPS and any other difficult airway situation. In our personal experience of adult airway assessment, we feel HMA close to zero or less than zero indicates a larynx that is not high. HMA could be considered as another important adjunct in upper airway assessment; however, holistic airway assessment should include both upper and lower airways. 


\subsection{Limitations of the Study}

\subsubsection{Head and Neck Position}

Most of our MPS patients had cervical spine issues so we chose to take radiological images at the neutral position of the head, keeping patient comfort as the priority. To keep the upper airway open, the natural instinct of any patient is to adopt a sniffing posture. In all our MPS patients, some form of airway and cervical spine abnormality was noted, which may have prompted patients to adopt a comfortable posture. These factors could have skewed some of our measurements. It may be argued that HMA, which is acute in the neutral comfortable position in MPS compared to non-MPS, may be more acute in a standard position of the head and neck. Future studies could include standardization of head positions to obtain radiological images to obtain accurate measures of the HMA and HMD to test this hypothesis. Extension of the neck will improve laryngoscopic views. Future studies could also incorporate measurement of HMA and HMD in maximum extension and comparison with HMA and HMD in the neutral position to assess the degree of improvement of laryngoscopy views by neck extension.

\subsubsection{Thyro-Hyoid Distance}

We made the assumption that the distance between the hyoid and thyroid is small enough to assume that HMD and TMD reflect the same measure of a high or anterior larynx. Future studies could also assess the thyrohyoid distance in flexion and extension of the neck to test this hypothesis.

\subsubsection{Numbers}

Our cohort examined only 50 adult MPS patients of various types and varying severity, which was compared with 50 adults with no upper airway issues. Considering the rarity of the disease, this may appear a significant number; however, a larger study group could have produced more significant results. Future studies may incorporate larger number of patients in both pediatric and adult MPS by a multi-center collaboration.

\subsection{Wider Implications}

HMD and HMA application can be extended to wider use of difficult airway assessment in any patient due to its simplicity in use. This may play a special role in those with cervical spine or any craniofacial anomalies.

\section{Conclusions}

HMA and HMD are useful measurements that can be obtained from existing crosssection imaging, providing important information about an anterior or high larynx. This is very helpful in pre-planning during airway assessment as part of the pre-operative workup. HMA may be a better indicator than HMD in MPS patients. The use of HMA and HMD can be extrapolated to airway assessments in other patients with or without head and neck dysmorphism. This simple airway assessment tool is a useful adjunct in the management of complex airways, such as adult MPS. Further investigation into the sensitivity and specificity of HMA and HMA with a standardized head position and its correlation with difficult intubation will be useful.

Author Contributions: Authors C.G. (Otolaryngologist), K.M.S. (Adult inherited Metabolic Medicine), G.T. (Anesthetist) come from different specialties with common interest in adult Mucopolysaccharidosis (MPS). C.G., G.T. have special interest with airway diseases came up with the conceptualization of this unique idea airway assessment in MPS. The methodology of the study was devised by C.G. and K.M.S. Formal analysis of the data was performed by C.G., K.M.S. The resources, data curation was performed by C.G., K.M.S., G.T.; writing original draft preparation by C.G.; writing-review and editing was performed by C.G., K.M.S., G.T. Visualization of the project was planned by C.G., K.M.S. The project was supervised by C.G. All authors contributed towards project administration. All authors have read and agreed to the published version of the manuscript. 
Funding: This research received no external funding, the article processing fee was supported by BioMarin Pharmaceutical Inc.

Institutional Review Board Statement: The study was conducted according to the guidelines of the Declaration of Helsinki, and Ethical approval from the local research and development department form Salford Royal NHS Foundation trust, Manchester, UK was obtained, reference: S20HIP40. The study did not involve any animals. This study was retrospective case notes review of adult patients.

Informed Consent Statement: Informed consent was obtained from all subjects involved in the study. However, no personal identifiable information has been used in this study.

Data Availability Statement: All the data required to understand and the data supporting reported results this project has been provided in the paper.

Acknowledgments: We would like to thank Amit Herwadkar, Consultant Radiologist, Salford Royal NHS foundation Trust, Manchester, UK, for his expertise in this project.

Conflicts of Interest: The authors declare no conflict of interest.

\section{References}

1. Mehta, A.B.; Winchester, B. Lysosomal Storage Disorders: A Practical Guide; Wiley-Blackwell Chichester: Hoboken, NJ, USA, 2012.

2. Mucopolysaccharidoses Fact Sheet. Available online: https://www.ninds.nih.gov/Disorders/Patient-Caregiver-Education/FactSheets / Mucopolysaccharidoses-Fact-Sheet (accessed on 31 July 2020).

3. Taylor, M.; Khan, S.; Stapleton, M.; Wang, J.; Chen, J.; Wynn, R.; Yabe, H.; Chinen, Y.; Boelens, J.J.; Mason, R.W. Hematopoietic stem cell transplantation for mucopolysaccharidoses: Past, present, and future. Biol. Blood Marrow Transplant. 2019, 25, e226-e246. [CrossRef] [PubMed]

4. Concolino, D.; Deodato, F.; Parini, R. Enzyme replacement therapy: Efficacy and limitations. Ital. J. Pediatrics 2018, 44, 117-126. [CrossRef] [PubMed]

5. Gadepalli, C.; Stepien, K.M.; Sharma, R.; Jovanovic, A.; Tol, G.; Bentley, A. Airway Abnormalities in Adult Mucopolysaccharidosis and Development of Salford Mucopolysaccharidosis Airway Score. J. Clin. Med. 2021, 10, 3275. [CrossRef]

6. Apfelbaum, J.; Hagberg, C.; Caplan, R.; Blitt, C.; Connis, R.; Nickinovich, D.; Benumof, J.; Berry, F. American Society of Anesthesiologists Task Force on Management of the Difficult Airway Practice guidelines for management of the difficult airway: An updated report by the American Society of Anesthesiologists Task Force on Management of the Difficult Airway. Anesthesiology 2013, 118, 251-270.

7. Patil, V. Predicting the difficulty of intubation utilizing an intubation gauge. Anesth. Rev. 1983, 10, 32-33.

8. Braunlin, E.A.; Harmatz, P.R.; Scarpa, M.; Furlanetto, B.; Kampmann, C.; Loehr, J.P.; Ponder, K.P.; Roberts, W.C.; Rosenfeld, H.M.; Giugliani, R. Cardiac disease in patients with mucopolysaccharidosis: Presentation, diagnosis and management. J. Inherit. Metab. Dis. 2011, 34, 1183-1197. [CrossRef]

9. Neufeld, E.; Muenzer, J. The mucopolysaccharidoses. In The Metabolic and Molecular Bases of Inherited Diseases, 8th ed.; Scriver, C.R., Beaudet, A.L., Sly, W.S., Valle, D., Childs, R., Kinzler, K.W., Eds.; McGraw-Hill: New York, NY, USA, 2001; pp. 3421-3452.

10. Valayannopoulos, V.; Nicely, H.; Harmatz, P.; Turbeville, S. Mucopolysaccharidosis vi. Orphanet J. Rare Dis. 2010, 5, 5. [CrossRef]

11. Berger, K.I.; Fagondes, S.C.; Giugliani, R.; Hardy, K.A.; Lee, K.S.; McArdle, C.; Scarpa, M.; Tobin, M.J.; Ward, S.A.; Rapoport, D.M. Respiratory and sleep disorders in mucopolysaccharidosis. J. Inherit. Metab. Dis. 2013, 36, 201-210. [CrossRef] [PubMed]

12. Muhlebach, M.S.; Wooten, W.; Muenzer, J. Respiratory manifestations in mucopolysaccharidoses. Paediatr. Respir. Rev. 2011, 12, 133-138. [CrossRef]

13. Crawley, S.; Dalton, A. Predicting the difficult airway. BJA Educ. 2015, 15, 253-257. [CrossRef]

14. Frerk, C.; Mitchell, V.S.; McNarry, A.F.; Mendonca, C.; Bhagrath, R.; Patel, A.; O'Sullivan, E.P.; Woodall, N.M.; Ahmad, I. Difficult Airway Society 2015 guidelines for management of unanticipated difficult intubation in adults. Br. J. Anaesth. 2015, 115, 827-848. [CrossRef]

15. Shiga, T.; Wajima, Z.i.; Inoue, T.; Sakamoto, A. Predicting difficult intubation in apparently normal patients: A meta-analysis of bedside screening test performance. J. Am. Soc. Anesthesiol. 2005, 103, 429-437. [CrossRef] [PubMed]

16. Mitchell, J.; Berger, K.I.; Borgo, A.; Braunlin, E.A.; Burton, B.K.; Ghotme, K.A.; Kircher, S.G.; Molter, D.; Orchard, P.J.; Palmer, J. Unique medical issues in adult patients with mucopolysaccharidoses. Eur. J. Intern. Med. 2016, 34, 2-10. [CrossRef]

17. Hendriksz, C.J.; Burton, B.; Fleming, T.R.; Harmatz, P.; Hughes, D.; Jones, S.A.; Lin, S.-P.; Mengel, E.; Scarpa, M.; Valayannopoulos, V. Efficacy and safety of enzyme replacement therapy with BMN 110 (elosulfase alfa) for Morquio A syndrome (mucopolysaccharidosis IVA): A phase 3 randomised placebo-controlled study. J. Inherit. Metab. Dis. 2014, 37, 979-990. [CrossRef] [PubMed]

18. Clarke, L.A.; Wraith, J.E.; Beck, M.; Kolodny, E.H.; Pastores, G.M.; Muenzer, J.; Rapoport, D.M.; Berger, K.I.; Sidman, M.; Kakkis, E.D. Long-term efficacy and safety of laronidase in the treatment of mucopolysaccharidosis I. Pediatrics 2009, 123, 229-240. [CrossRef] [PubMed] 
19. Harmatz, P.; Giugliani, R.; Schwartz, I.V.D.; Guffon, N.; Teles, E.L.; Miranda, M.C.S.; Wraith, J.E.; Beck, M.; Arash, L.; Scarpa, M. Long-term follow-up of endurance and safety outcomes during enzyme replacement therapy for mucopolysaccharidosis VI: Final results of three clinical studies of recombinant human N-acetylgalactosamine 4-sulfatase. Mol. Genet. Metab. 2008, 94, 469-475. [CrossRef]

20. Aldenhoven, M.; Wynn, R.F.; Orchard, P.J.; O’Meara, A.; Veys, P.; Fischer, A.; Valayannopoulos, V.; Neven, B.; Rovelli, A.; Prasad, V.K. Long-term outcome of Hurler syndrome patients after hematopoietic cell transplantation: An international multicenter study. Blood J. Am. Soc. Hematol. 2015, 125, 2164-2172. [CrossRef] [PubMed]

21. Baker, P.; Depuydt, A.; Thompson, J. Thyromental distance measurement-fingers don't rule. Anaesthesia 2009, 64, 878-882. [CrossRef] [PubMed]

22. Al Ramadhani, S.; Mohamed, L.; Rocke, D.; Gouws, E.; Ramadhani, S. Sternomental distance as the sole predictor of difficult laryngoscopy in obstetric anaesthesia. Br. J. Anaesth. 1996, 77, 312-316. [CrossRef]

23. Braunlin, E.; Steinberger, J.; DeFor, T.; Orchard, P.; Kelly, A.S. Metabolic syndrome and cardiovascular risk factors after hematopoietic cell transplantation in severe mucopolysaccharidosis type I (Hurler syndrome). Biol. Blood Marrow Transpl. 2018, 24, 1289-1293. [CrossRef] [PubMed]

24. Lin, H.-Y.; Lee, C.-L.; Chiu, P.C.; Niu, D.-M.; Tsai, F.-J.; Hwu, W.-L.; Lin, S.J.; Lin, J.-L.; Chang, T.-M.; Chuang, C.-K. Relationships among Height, Weight, Body Mass Index, and Age in Taiwanese children with different types of mucopolysaccharidoses. Diagnostics 2019, 9, 148. [CrossRef]

25. Wilson, M.; Spiegelhalter, D.; Robertson, J.; Lesser, P. Predicting difficult intubation. Br. J. Anaesth. 1988, 61, 211-216. [CrossRef]

26. Mallampati, S.R.; Gatt, S.P.; Gugino, L.D.; Desai, S.P.; Waraksa, B.; Freiberger, D.; Liu, P.L. A clinical sign to predict difficult tracheal intubation; a prospective study. Can. Anaesth. Soc. J. 1985, 32, 429-434. [CrossRef]

27. Huang, H.-H.; Lee, M.-S.; Shih, Y.-L.; Chu, H.-C.; Huang, T.-Y.; Hsieh, T.-Y. Modified Mallampati classification as a clinical predictor of peroral esophagogastroduodenoscopy tolerance. BMC Gastroenterol. 2011, 11, 12. [CrossRef]

28. Dalewski, B.; Kamińska, A.; Syrico, A.; Kałdunska, A.; Pałka, Ł.; Sobolewska, E. The Usefulness of Modified Mallampati Score and CT Upper Airway Volume Measurements in Diagnosing OSA among Patients with Breathing-Related Sleep Disorders. Appl. Sci. 2021, 11, 3764. [CrossRef]

29. Cormack, R.; Lehane, J. Difficult tracheal intubation in obstetrics. Anaesthesia 1984, 39, 1105-1111. [CrossRef] [PubMed]

30. Yentis, S. The effects of single-handed and bimanual cricoid pressure on the view at laryngoscopy. Anaesthesia 1997, 52, 332-335. [CrossRef] [PubMed]

31. Cook, T. A new practical classification of laryngeal view. Anaesthesia 2000, 55, 274-279. [CrossRef]

32. Jain, K.; Gupta, N.; Yadav, M.; Thulkar, S.; Bhatnagar, S. Radiological evaluation of airway-What an anaesthesiologist needs to know! Indian J. Anaesth. 2019, 63, 257-264. [PubMed]

33. Hui, C.; Tsui, B. Sublingual ultrasound as an assessment method for predicting difficult intubation: A pilot study. Anaesthesia 2014, 69, 314-319. [CrossRef]

34. Ezri, T.; Gewürtz, G.; Sessler, D.; Medalion, B.; Szmuk, P.; Hagberg, C.; Susmallian, S. Prediction of difficult laryngoscopy in obese patients by ultrasound quantification of anterior neck soft tissue. Anaesthesia 2003, 58, 1111-1114. [CrossRef] [PubMed]

35. Sharma, R.; Tol, G.; Stepien, K.; Yadthore, S.; Watson, S.; Samraj, P.; Gadepalli, C. Role of 3-dimensional (3D) reconstruction of radiology images and virtual endoscopy in the assessment of airways in adult mucopolysaccharidosis patients. Mol. Genet. Metab. 2020, 129, S147-S148. [CrossRef]

36. Gadepalli, C.; Tol, G.; Yadthore, S.; Sharma, R.; Jovanovic, A.; Palmer, J.; Stepien, K.M. Nasendoscopy findings in adult patients with mucopolysaccharidosis: A tertiary UK centre experience. Mol. Genet. Metab. 2020, 129, S59-S60. [CrossRef]

37. Han, Y.; Tian, Y.; Zhang, H.; Zhao, Y.; Xu, M.; Guo, X. Radiologic indicators for prediction of difficult laryngoscopy in patients with cervical spondylosis. Acta Anaesthesiol. Scand. 2018, 62, 474-482. [CrossRef] [PubMed] 